\title{
LITERATURA DE NO FICCIÓN Y DISCURSO JUDICIAL: ¿LAS NARRATIVAS PROCESALES TOLERAN LOS FINALES ABIERTOS?
}

\begin{abstract}
Alícia RUiZ
RESUMo: La lectura de Operación Masacre de R. Walsh - obra maestra de literatura de no ficción en la Argentina - habilita la pregunta acerca de si las narrativas procesales admiten más de un final o finales abiertos. Una categoría propia del análisis literario como lo es la de "final abierto" es utilizada para reflexionar acerca del discurso judicial y sus reglas de formación; para marcar ciertas semejanzas entre el juez, el periodista y el escritor pensados como narradores; la contingencia de la verdad que es contada y, por fin, el cruce entre política, historia y derecho.
\end{abstract}

PalaVRas-Chave: ficción y verdad; final abierto; juez narrador; literatura de no ficción; el proceso como juego.

\begin{abstract}
"Esta es la historia que escribo en caliente y de un tirón, para que no me ganen de mano pero que después se me va arrugando día a día en un bolsillo porque la paseo por todo Buenos Aires y nadie me la quiere publicar, y casi no enterarse." (Walsh, 1972, p. 20)

“...Por eso estaba lanzado a un aprendizaje cotidiano: vivir como si su existencia fuese una larga partida, ponderando cada una de sus movidas, por inocuas que pareciesen; y también sus inacciones, porque no hacía falta desplazar una pieza para arriesgarla. ¿Cuántas probabilidades tiene un peón de liderar una estrategia sin ser comido durante el proceso?" (Figueras, 2017, p. 242-243).
\end{abstract}

1 Profesora Titular Regular de Teoría General y Filosofia del Derecho de la Facultad de Derecho de la Universidad de Buenos Aires. Jueza del Tribunal Superior de Justicia de la Ciudad Autónoma de Buenos Aires. Coordinadora de la Oficina de Género del Tribunal Superior de Justicia de la Ciudad Autónoma de Buenos Aires. Buenos Aires, Argentina. Email: vruiz@tsjbaires.gov.ar. 


\section{INTRODUCIÓN}

Voy a trabajar con una obra Operación Masacre de Rodolfo Walsh, sin duda el modelo argentino de la literatura de la no ficción cuya primera edición es de 1957.

Y con una novela publicada en 2016 que tiene a Walsh como protagonista y en la que se cuenta (o se imagina) cómo y bajo qué circunstancias concibió y produjo Operación Masacre. El negro corazón del crimen de Marcelo Figueras (otro argentino) quien propone que su obra sea entendida como “... un homenaje a ese hombre. A quien asesinaron hace cuarenta años sin que eso impida que escriba y piense cada vez mejor" (Figueras, 2017, p. 412).

Una ficción cuyo eje es una no ficción. Una vuelta de la literatura sobre sí misma que duplica en simultáneo un momento trágico de la historia de mi país.

Operación Masacre fue siendo escrita al hilo de una investigación que Walsh inicia de manera inesperada. Los capítulos del libro aparecieron antes como artículos periodísticos y luego como folletín.

Cuando buscaba como hacer conocer lo ocurrido el 9 de junio de 1956 el Director del Semanario Mayoría le propuso - escribe Figueras:

\footnotetext{
A lo mejor se puede publicar por entregas - dijo Jacovella -. Como los folletines de antes. Erre se quedó mudo. Era la mejor de las opciones; tanto, que ni siquiera se había animado a darle forma en su mente. De ese modo pondría a circular el texto pronto. iNi siquiera tenía que tener el libro terminado para empezar a hacerlo! (Figueras, 2017, p. 311).
}

El texto fue cambiando en sucesivas ediciones, al compás de desmentidas, réplicas, apéndices, corolarios y la propia evolución política y militante de Walsh. Cuatro son las ediciones que registran los cambios en la construcción del libro, la de 1957, la de 1964, la tercera de 1969, y la cuarta y definitiva edición del libro en 1972, con la conocida portada con una reproducción en toda su superficie y en blanco negro del cuadro "El 3 de mayo" de Goya. Al cabo de la tercera edición el relato señala la continuidad de la lucha del peronismo luego de su derrocamiento en el golpe cívicomilitar de 1955, desde los fusilamientos de 1956, hasta la ejecución del general Aramburu en 1970. 
Walsh escribe el libro un poco a tientas, intentando encontrar un lugar que consideraba ya perdido o intentando encontrar un lugar diferente a aquel en el que estaba. No sospechará hasta muchos años más tarde (lo leemos en su Diario), que después de Operación Masacre ese lugar ya no existe. Operación Masacre es un monumento también, porque habla de ese no lugar de la literatura, de lo literario como dispersión o como suplemento, de la escritura como escándalo de la razón y la ley (Link, 2011, [ s. p.]).

Un libro era una voz y algo más: la forma física que esa voz había adoptado para expresarse, para hacerse oír. Por eso le había insistido a Erre para que terminase: porque, aunque no hubiesen obtenido justicia, la mera existencia del libro marcaría una diferencia. El libro sería un altar al que los deudos acudirían para venerar a sus muertos. El libro les confirmaría a los sobrevivientes que lo padecido no había sido en vano, que su odisea devendría testimonio. El libro marcaría un antes y un después para los involucrados, sería la expresión palpable de un cambio metafísico: lo que habían descubierto respecto de sí mismos al cabo de aquella experiência (Figueras, 2017, p. 387-388)

En todo momento está claro que el autor está preocupado por contar la realidad y no por hacer literatura:

Walsh pone en el centro de su obra la imposibilidad (histórica pero también lógica) de la novela. No hay novela. Y porque no hay novela es que esta obra existe y permanece como una piedra difícil de tallar. Walsh escribe Operación Masacre como un texto monumental. Ese texto es monumental por varias razones: por ejemplo, porque se anticipa en seis, ocho, diez años al non-fiction que tantos réditos daría a Truman Capote y Norman Mailer (Link, 2011, [s.p.]).

\section{II.}

Parece imprescindible recordar un poco de la historia argentina contemporánea porque "El sentido de la ficción no es solo lingüístico, depende de referencias externas del relato, y de la situación extraverbal" (Piglia, 2016, p. 181) y desde luego "de una lectura capaz de reponer el contexto y descifrar los sobrentendidos de la historia” (Piglia, 2016, p. 181).

En septiembre de 1955 Perón es separado de su cargo por un golpe de Estado que dio en llamarse Revolución Libertadora. Asume un gobierno militar que en junio de 1956 sofoca un levantamiento de fuerzas armadas leales a Perón y ordena el fusilamiento del General Valle y de otros militares y civiles. La historia oficial difundida por los medios de comunicación de la 
época silenciaron y luego desvirtuaron lo ocurrido, en especial el asesinato de personas inocentes apresadas sin orden judicial ni ley marcial vigente.

El 9 de junio de 1956 cinco civiles fueron clandestinamente fusilados sospechados de estar en el alzamiento, en un terreno descampado de José León Suárez, en el conurbano de Buenos Aires.

Los fusilamientos quedaron impunes, pero Operación Masacre reveló lo sucedido, destruyó la versión oficial, creó un nuevo género literario y cambió para siempre la vida de su autor. El Walsh investigador visibiliza lo ocultado, el Walsh narrador relata esa investigación en clave política y literaria y de algún modo impulsa y sostiene la denuncia judicial de Juan Carlos Livraga, uno de los sobrevivientes.

III.

En Operación Masacre la historia oral se hace historia escrita... y el expediente judicial se vuelve literatura. Allí están los testimonios de los vivos, de sus familias junto a las de aquellos que no se salvaron, el allanamiento de la casa donde todos se encontraban la noche del 9 de junio de 1956 escuchando por radio una pelea de box, la tremenda escena del crimen. La violencia de lo ocurrido se actualiza en la lectura por la técnica narrativa que Walsh le imprime a la novela: lo que se conoce y lo que no se conoce; lo que se sabe y lo que no se sabe; las preguntas que se formula el autor en el intento de interpretar la realidad que cuenta: "El relato gira alrededor de un vacío, de algo enigmático que es preciso descifrar, y el texto yuxtapone rastros, datos, signos, hasta armar un gran caleidoscopio que permite captar fragmentos de la realidad" (Piglia, 2016, p. 184)².

La obra se divide en tres partes $\left(1^{\mathrm{a}}\right.$ parte: Las personas; $2^{\mathrm{a}}$ : Los hechos y $3^{\mathrm{a}}$ : La evidencia), y cada una de ellas en capítulos. El prólogo (los prólogos) tiene/n una entidad que los excede, como se verá un poco más adelante. En sucesivas ediciones al epílogo provisorio de la primera edición se incorpora otro epílogo y un fin del epílogo en la tercera edición. Prólogos y epílogos resignifican Operación Masacre y muestran la transformación de Rodolfo Walsh como hombre y como escritor.

2 "Muñiz tenía razón. Los fusilamientos habían sido un acto sacrificial. Y las víctimas propiciatorias, los corderos cuya sangre desbordó las jofainas, eran los Rodríguez, los Carranza, los Garibotti. Livraga y los demás habían ligado un sopapo por chambonees, no más. Se habían rodeado de malas compañías - de rebeldes” (Figueras, 2017, p. 293). 
La primera parte «Las Personas» retrata en cada capítulo uno por uno de los que fueron apresados 3 .

En la segunda parte «Los Hechos»: lo que pasó desde el allanamiento, las detenciones, el fusilamiento y lo ocurrido con los sobrevivientes.

A las 23:30 del 9 de junio de 1956, el jefe de la policía de la Provincia de Buenos Aires Teniente coronel Desiderio Fernández Suarez (responsable

3 Las personas:

1. Carranza (muerto) - "Era peronista y estaba prófugo" e cesante; era ferroviario y había perdido su trabajo; su mujer quería que se entregara y él "se refugiaba en afirmaciones duras, serias, definitivas: - No he robado. No he matado. No soy un delincuente"; 6 hijos, Elena, la mayor, ya estuvo presa (Walsh, 1972, p. 29-32).

2. Garibotti (muerto) - casado, 38 años, 6 hijos, ferroviário; lo busca Carranza; "No lleva armas encima y en ningún momento las tendrá en sus manos. También Carranza va desarmado" (Walsh, 1972, p. 32-35).

3. Don Horacio Di Chiano (sobreviviente) - alrededor de 50 años, hace 17 que trabaja como electricista en ITALO, clase media; dueño de la finca "donde se desarrollará el primer acto del drama..."; tiene dos departamentos: Don Horacio vive al frente y el pasillo que llega hasta el fondo "es tan angosto" que solo se puede caminar en fila india (Walsh, 1972, p. 36-39).

4. Giunta (sobreviviente) - menos de 30 años, vecino de Don Horacio; trabaja hace 15 años en una zapatería en Bs. As.; no está en el departamento del fondo (Walsh, 1972, p. 39-40).

5. Díaz (sobreviviente) - suboficial, sargento sastre retirado de la Marina, casado, 2 o 3 hijos, provinciano, de edad indefinible, conversador (Walsh, 1972, p. 40-41).

6. Lizaso (muerto) - 21 años, de carácter retraído y tímido, tenía un padre que era peronista una vez, abandonó sus estudios secundarios y ayuda a su padre martillero jugador fuerte, no lleva armas; no se sabe con claridad cómo piensa salvo que "esa noche" al despedirse de su novia le deja una nota: "si todo sale bien esa noche. "Pero todo saldrá mal" (Walsh, 1972, p. 42-43).

7. Marcelo (sobreviviente) - ex-terrorista, amigo de la familia Lizaso y de otros protagonistas; "Marcelo" el hombre que trata de llevarse a Lizazo más de una vez de la casa de Florida (Walsh, 1972, p. 44-45).

8. Gavino (sobreviviente) - alrededor de 40 años, está en el levantamiento, suboficial de gendarmería en una época, más tarde vendedor de terrenos; viene conspirando desde hace tiempo; prófugo, su mujer es encarcelada como rehén, se refugia en el depto. de Torres (Walsh, 1972, p. 45-46).

9. Juan Carlos Torres (sobreviviente) - el inquilino del departamento del fondo; lleva dos o tres vidas distintas: para el vecindario es un muchacho tranquilo y popular, para la policía es un individuo peligroso y escurridizo; Walsh lo encuentra asilado en una embajada latinoamericana meses después de los fusilamientos; "hombre parco, decidido y extremadamente cauteloso" (Walsh, 1972, p. 46-48).

10. Mario (muerto) - 33 años, serio y trabajador, Ooficinista, con algunas aspiraciones culturales, vecino que se ocupa de las cosas del barrio; un amigo (no se sabe quién) lo invita a ver la pelea, le avisa a su mujer (tiene un hijo) y se va; vive "a menos de $100 \mathrm{mts}$ de la casa fatídica" (Walsh, 1972, p. 48-50).

11. Livraga (sobreviviente) - hijo de un constructor; vVive en el barrio; dejó los estudios secundarios; 24 años (casi); trabaja de colectivero; niega haber sabido algo de la revolución, y no hay un solo testigo que lo indique como comprometido o enterado; "La casualidad decide por él. La casualidad que le sale al paso en la persona de su amigo" (Walsh, 1972, p. 50-52).

12. Vicente Rodríguez (muerto) - 35 años, casado, 3 hijos, carga bolsas en el puerto; alguna vez fue delegado. (Walsh, 1972, p. 52-54). 
directo de la tragedia) 4 allana una casa en la localidad de Florida y detiene a doce civiles que supone implicados en la rebelión. Unas seis horas después, antes de amanecer, los detenidos fueron llevados desde la comisaría de San Martín a un basural de José León Suárez, en el conurbano de Buenos Aires, donde les dispararon con la intención de matarlos. Cinco (Nicolás Carranza, Francisco Garibotti, Carlos Alberto Lizaso, Mario Brión y Vicente Damían Rodríguez) fueron asesinados y siete (Reinaldo Benavidez, Rogelio Díaz, Horacio Di Chiano, Norberto Gavino, Miguel Ángel Giunta, Juan Carlos Livraga y Julio Troxler) sobrevivieron, algunos con graves lesiones.

Algunos párrafos alcanzan para trasmitir el horror de la matanza:

Una cosa llama fuertemente la atención. Las policías van armados de simples máuseres. Para la misión que llevan, y en las circunstancias en que la van a cumplir, es casi incomprensible [...] Enigma de difícil respuesta. Lo indudable es que gracias a esa afortunada circunstancia y a otras igualmente extrañas que veremos luego - la mitad de los condenados salvarán la vida [...]

Hace un frio cruel. La temperatura se mantiene en cero grados [...]

- Yo creo que nos matan, don Lito - dice Brión (Walsh, 1972, p. 86-87).

De un lado la calle tiene una hilera de eucaliptus, que se recortan altos y tristes contra el cielo estrellado. Del otro, a la izquierda, se extiende un amplio baldío, un depósito de escorias, el siniestro basural de José León Suárez, cortado de zanjas anegadas en invierno, pestilente de mosquitos y bichos insepultos en verano, corroído de latas y chatarra.

Por el borde del baldío hacen caminar a los detenidos. Los vigilantes los empujan con los cañones de los fusiles. La camioneta entra en la calle y les alumbra las espaldas con los faros.

Ha llegado el momento... (Walsh, 1972, p. 90).

Ha llegado el momento. Lo señala un dialogo breve, impresionante.

-¿Qué nos van a hacer? -pregunta uno.

-iCamine para adelante! -le responden.

-iNosotros somos inocentes! -gritan varios.

\footnotetext{
"El hombre de uniforme militar, voz de borracho y mano larga que había mandado a fusilar a Juan Carlos se llamaba Desiderio Fernández Suárez. Era teniente coronel. Y desde que la Libertadora asumió el poder manejaba la policía de la provincia de Buenos Aires. Era el jefe y el villano a la vez" (Figueras, 2017, p. 88); "Están subiendo la amplia escalinata que da a la plaza Rivadavia cuando Fernández Suárez se dirige a un subordinado y en voz que todos escuchan da la orden: -iA esos detenidos de San Martín, que los lleven a un descampado y los fusilen! Parece que no basta. Fernández Suárez debe acudir personalmente al transmisor. Rodríguez Moreno recibe la orden. Inapelable. Y se decid." (Walsh, 1972, p. 83).
} 
-No tengan miedo -les contestan-. No les vamos a hacer nada.

iNO LES VAMOS A HACER NADA!

Los vigilantes los arrean hacia el basural como a un rebaño aterrorizado. La camioneta se detiene, alumbrándolos con los faros. Los prisioneros parecen flotar en un lago vivísimo de luz. Rodríguez Moreno baja, pistola en mano (Walsh, 1972, p. 91).

Había salido el sol sobre el tétrico escenario del fusilamiento. Los cadáveres estaban dispersos en las inmediaciones de la ruta. Algunos habían caído en una zanja y la sangre que tenía el agua estancada parecía convertirla en un alucinante río donde flotaban hilachas de masa encefálica. Tiempo después vaciaron allí un camión de alquitrán y otro de cal...

Por todas partes había cápsulas máuser. Durante muchos días los chicos de la zona las vendieron a los visitantes curiosos. En varias casas lejanas quedaron impactos de balas perdidas.

Los primeros en detenerse junto al camino aquella mañana fueron los desprevenidos pobladores que iban a sus ocupaciones. Después se corrió la voz por el pueblo y una muchedumbre espantada y sombría se fue congregando en torno al pavoroso espectáculo (Walsh, 1972, p. 106).

La tercera parte «La Evidencia» "narra el expediente judicial" a través de la transcripción de documentos y actuaciones que se cumplieron durante el proceso, en muchas de las cuales los aportes del Walsh investigador fueron determinantes de lo que pudo ser el final de la historia. Y que no fue.

Importa especialmente señalar que el juez Hueyo que recibió la denuncia reunió pruebas y encaminó la causa hacia la condena de los militares y policías involucrados, pero el poder político apoyado por el dictamen del Procurador General de la Nación (un jurista de nota Sebastián Soler) y por la Corte Suprema en fallo unánime le quitó competencia a favor de la justicia militar aduciendo que los fusilamientos se ejecutaron cuando la ley marcial había sido promulgada (lo que era falso y estaba acreditado por la declaración judicial del propio jefe de la Policía)5.

5 "La prueba reunida en varios meses de investigación me permitió acusar a Fernández Suárez de asesinato, cosa que hice hasta la monotonía, sin que se dignara a querellarme. Había algo, sin embargo, que faltaba a esa prueba, y era el expediente instruido en La Plata por el juez Belisario Hueyo, a raíz de la denuncia de Livraga. Conocía el tenor general de ese expediente, pero sólo tuve en mis manos una copia fotográfica cuando estaba publicada la primera edición de este libro (1957). Pude entonces confrontar las dos investigaciones, la que hizo el juez y la que hice yo. Prácticamente se superponen y complementan. En algunos aspectos, la mía era más detallada: abarcaba declaraciones firmadas por los sobrevivientes. Troxler, Benavidez y Gavino, que estaban en Bolivia y a quienes el doctor Hueyo no pudo tomar declaración; Interrogatorios a Horacio di Chiano, 
El prólogo de Operación Masacre de la edición de 1972 es más que una referencia al origen de la investigación.

Walsh habla de la masacre, de sí mismo, del escritor y periodista que era y del impacto emocional e ideológico que lo volvió otro. Es un ejercicio fascinante descubrir los diferentes planos que se conjugan en ese texto anticipando la novela íntegra. Y cómo dramáticamente desde el inicio, verdad y ficción corren en paralelo.

No hay respiro para el lector que se siente identificado y comprometido con los que mueren y con los que sobreviven; indignado con los asesinos y con sus cómplices y azorado porque sabe que no puede escapar a lo que Walsh quiso evitar:

Escribí este libro para que fuera publicado, para que actuara [...] investigué y relaté estos hechos tremendos para darlos a conocer en la forma más amplia, para que inspiren espanto para que no puedan jamás volver a repetirse (1972, p. 17).

La primera noticia sobre los fusilamientos clandestinos de junio de 1956 me llegó en forma casual, a fines de ese año, en un café de La Plata donde se jugaba al ajedrez, se hablaba más de Keres o Nimzovitch que de Aramburu y Rojas, y la única maniobra militar que gozaba de algún renombre era el ataque a la bayoneta de Schlechter en la apertura siciliana.

En ese mismo lugar, seis meses antes, nos había sorprendido una medianoche el cercano tiroteo con que empezó el asalto al comando de la segunda división y al departamento de policía, en la fracasada revolución de Valle. Recuerdo cómo salimos en tropel, los jugadores de ajedrez, los jugadores de codilo y los parroquianos ocasionales, para ver qué festejo era ése, y cómo a medida que nos acercábamos a la Plaza San Martín nos íbamos poniendo más serios y éramos cada vez menos, y al fin cuando crucé la plaza, me vi solo, y cuando entré a la estación de ómnibus ya fuimos de nuevo unos cuantos, inclusive un negrito con uniforme de vigilante que se había parapetado detrás de unas gomas y decía que, revolución o no, a él no le iban a quitar el arma, que era un notable Mauser del año 1901.

Recuerdo que después volví a encontrarme solo, en la oscurecida calle 54, donde tres cuadras más adelante debía estar mi casa, a la que quería llegar y finalmente llegué dos horas más tarde, entre el aroma de los tilos que

Torres, 'Marcelo', docenas de testigos menores que no pasaron por el despacho judicial; y una copia fotostática del libro de locutores de Radio del Estado, estableciendo la hora en que se promulgó la ley marcial. En otros aspectos, el expediente Livraga va más lejos de lo que yo hubiera podido imaginar. Además de ser la historia oficial del caso, contiene las confesiones de los ejecutores materiales. Es ese expediente, pues, el que a partir de la segunda edición (1964) invoco como prueba" (Walsh, 1972, p. 140). 
siempre me ponía nervioso, y esa noche más que otras. Recuerdo la incoercible autonomía de mis piernas, la preferencia que, en cada bocacalle, demostraban por la estación de ómnibus, a la que volvieron por su cuenta dos y tres veces, pero cada vez de más lejos, hasta que la última no tuvieron necesidad de volver porque habíamos cruzado la línea de fuego y estábamos en mi casa. Mi casa era peor que el café y peor que la estación de ómnibus, porque había soldados en las azoteas y en la cocina y en los dormitorios, pero principalmente en el baño, y desde entonces he tomado aversión a las casas que están frente a un cuartel, comando o un departamento de policía.

Tampoco olvido que, pegado a la persiana, oí morir a un conscripto en la calle y ese hombre no dijo: "Viva la pátria» sino que dijo: 'No me dejen solo, hijos de puta'.

Después no quiero recordar más, ni la voz del locutor en la madrugada anunciando que dieciocho civiles han sido ejecutados en Lanús, ni la ola de sangre que anega al país hasta la muerte de Valle. Tengo demasiado para una sola noche. Valle no me interesa. Perón no me interesa, la revolución no me interesa. ¿Puedo volver al ajedrez?

Puedo. Al ajedrez y a la literatura fantástica que leo, a los cuentos policiales que escribo, a la novela 'seria' que planeo para dentro de algunos años, y a otras cosas que hago para ganarme la vida y que llamo periodismo. La violencia me ha salpicado las paredes, en las ventanas hay agujeros de balas, he visto un coche agujereado y adentro un hombre con los sesos al aire, pero es solamente el azar lo que me ha puesto esto ante los ojos. Pudo ocurrir a cien kilómetros, pudo ocurrir cuando yo no estaba.

Seis meses más tarde, una noche asfixiante de verano, frente a un vaso de cerveza, un hombre me dice:

-Hay un fusilado que vive.

No sé qué es lo que consigue atraerme en esa historia difusa, lejana, erizada de improbabilidades. No sé por qué pido hablar con ese hombre, por qué estoy hablando con Juan Carlos Livraga.

Poco después sé. Miro esa cara. El agujero en la mejilla, el agujero más grande en la garganta, la boca quebrada y los ojos opacos donde se ha quedado flotando una sombra de muerte. Me siento insultado, como me sentí sin saberlo cuando oí aquel grito desgarrador detrás de la persiana. Livraga me cuenta su historia increíble; la creo en el acto. Así nace aquella investigación, este libro [...] ahora, durante casi un año no pensaré en otra cosa [...] y a cada momento las figuras del drama volverán obsesivamente" (1972, p. 17-19).

IV.

El subtítulo de Operación Masacre pudo ser "lo imposible es verdadeiro". O mejor "Hay un fusilado que vive o lo imposible es verdadero".

En una novela "hay muchas voces y personajes que hablan, hay documentos, pero parece que nadie narrara” (Piglia, 2016, p. 211). 
La relación entre novela y narración es el narrador según Benjamín, una figura que ya con Flaubert "va minando su lugar de autoridad y de garantía de verdad". Tanto que en la obra de ciertos autores se advierte "la desaparición o el vacío del lugar del narrador" (Piglia, 2016, p. 211).

Algo de todo esto ocurre en el expediente judicial. Hay distintas voces, personajes que hablan, documentos que se ofrecen, se agregan, se exhiben para su reconocimiento.

Y si en el juicio quien narra es el juez, hoy su relato no genera confianza ni respeto. Ese desvanecimiento del personaje acarrea consecuencias graves y no previstas o imposibles desde los códigos que ordenan la narración procesal.

Walsh lo advertía: "Mi experiencia personal con los jueces, en cuanto periodista, no ha sido alentadora. Podría nombrar una docena a quienes conozco como individuos facciosos, ineptos o simplemente corrompidos. Prefiero señalar como ejemplo de decisión, rapidez y eficacia la actuación que tuvo en este caso el juez Hueyo" (1972, p. 140).

La ficción jurídica es el camino real para acceder a la verdad. De la ficción jurídica a la no ficción de lo real. Un real que además se exhibe como incuestionablemente verdadero. Toda esta serie de operaciones se suceden "naturalmente" a lo largo de la investigación y del juicio y cierran en la decisión (sentencia). Y como el fusilado que no ha muerto la sentencia consagra a la imposibilidad como única verdad.

Hay un efecto retrospectivo en la escritura, esto es, su capacidad de "actuar" ahora y hacia atrás (resignificar, predisponer, re-ferir); y un efecto "verdadero" en la "escritura jurídica", compartido (en términos de investigación) con cierto periodismo y cierta literatura, vale decir, la construcción no sólo del hecho sino de una autoridad "por fuera" del hecho construido; y ese carácter, a falta de mejor término, "tramado" del discurso jurídico: una "trama" de disciplinas y saberes que no se exponen como tales y una "trama" (nudo, punto ciego, obstáculo: real) de poderes sociales no evidenciados y muchas veces no evidenciables.

Las narrativas procesales se organizan vinculando selectivamente lo fáctico, lo normativo... y mucho más. La red de sentidos que conforman la trama logra aparecer como puro derecho metabolizando los muchos discursos sociales que le dan consistencia y dicen la "verdad". 
Aquí Foucault hace lo suyo y casi con ironía, descubre el oscuro entramado entre discurso jurídico y verdad, bajo la forma de un problema:

o, mejor, un as anudado de manera más o menos torpe por la pregunta: ¿Cuáles son el lugar y el papel del Decir veraz en la práctica judicial? [...] Ya se trate de los procedimientos de instrucción o los considerandos de un fallo, del recurso a los testimonios o las pericias, de los alegatos o las declaraciones de culpabilidad, de la interpretación de la ley o la consideración del estado de las costumbres o los datos económicos, la práctica judicial otorga un lugar destacado al Decir veraz, y bajo formas notablemente diversas [...] digamos, sin agresividad alguna: la verdad no le facilita la vida al derecho, y menos aún al derecho penal (Foucault, 2014, p. 31).

En una investigación periodística como en una novela policial hay un "hecho" real o misterioso que se construye. El estilo con que se construye produce efectos distintos; tanto los datos que se prefieren cuanto los que se ignoran u ocultan hilvanan la "trama" que relaciona "selectivamente" los motivos que explican lo que pasó:

Igual que en la literatura fantástica [...] se persigue lo imposible y la construcción del enigma supone descubrir un elemento que parece impensable y reconstruir las razones por las cuales parece impensable. Operación Masacre es eso: un acontecimiento que no tiene explicación, cuya causalidad es necesario reconstruir porque ha sido desplazada o distorsionada por un trabajo de encubrimiento realizado por el poder político (Piglia, 2016, p. 199).

Y así sucede también en un proceso. El "tipo de construcción” o "el estilo" si se quiere, facilitan el descubrimiento "de un elemento que parecía imposible" o por el contrario, lleva a que se descarten todas las evidencias que hubieran permitido su "existencia" garantizando así la imposibilidad de poner en cuestión lo que parecía verdadero o "más verosímil”?

Construir la realidad y hacerla creíble es producción discursiva sometida a reglas que habilitan algunas líneas y estrategias narrativas y clausuran otras. Las que valen para el mundo del derecho son peculiares, sutiles y rigurosas pero siempre permeadas por la polisemia de las palabras y la resignificación de los textos cuando - como es inevitable - ni unas (las palabras) están sueltas ni los otros (los textos) están aislados.

Como dice Marí:

¿Con que categorías conceptuales hay que dar cuenta de la presencia en el campo de producción semántico del 
derecho de otros discursos que, no obstante ser distintos en su origen, forma y función, lo determinan y fijan las condiciones de su aparición material?

¿Cuál es el principio de control de la producción del discurso jurídico que hace que estos otros discursos, después de haber intervenido como trama o como urdimbre en el período de su constitución, desaparezcan del producto final formado o se releguen a una esfera evanescente y secundaria de mera 'auxiliaridad'?

¿Cuál es la regla de formación del discurso jurídico que al mismo tiempo entrelaza y criba otros discursos, los incorpora y expulsa a la vez de su dominio, los aplica y debilita, los integra y frustra, organiza su campo semántico con ellos y los desconoce acto seguido para lograr la identidad de su especificidad? (1993, p. 252).

Tanto la literatura de no ficción como el discurso judicial (investigación, juicio, sentencia) están marcados por los grandes relatos sociales, y por la incidencia brutal, distorsionadora de lo que los medios de comunicación de masas aluden o eluden en su propio discurso. Y ambos comparten "el manejo de un elemento documental, de una historia de vida real y el contraste entre esa historia documental y la voz ficcional que la refiere" (Piglia, 2016, p. 151).

Y hay más similitudes: la relación entre texto e imaginario social, el lugar de la utopía, de la verdad y la ficción que Piglia formula respecto de la literatura de no ficción aplican al discurso judicial:

No es posible definir el funcionamiento del género sin tener presente la tensión que la novela mantiene, desde su origen, con este campo del imaginario colectivo que es la ilusión social. En una sociedad tiene mucha importancia lo que todavía no es, lo que no existe, aquello de lo cual se habla ya sea porque no se quiere que exista o porque sí se quiere. Ese lugar es básico: es el lugar de la utopía, pero también el del procedimiento del terror - si pensamos en el discurso estatal, que tiende a construir lo posible sobre la base del temor -. En el discurso estatal de nuestro país, lo que todavía no es suele funcionar como el retorno. El temor al futuro está construido sobre la base de que puede ser igual que el pasado. En la política, el discurso de lo posible tiende a poner como amenaza lo que ya fue (Piglia, 2016, p. 62).

Piglia escribe parafraseando a Lacan:

la verdad tiene la estructura de una ficción donde otro habla. Hay que hacer en el lenguaje un lugar para que el otro pueda hablar. La literatura sería el lugar en el que siempre es otro el que habla. Me parece, entonces, que podríamos imaginar que hay un estilo en Walsh que yo llamaría el desplazamiento, la distancia. Salir del centro, dejar que el lenguaje hable también en el borde, en lo que se oye, en lo que llega de otro (Piglia, 2016, p. 180). 
V.

La cuestión del final o los finales es lo que me gustaría mencionar ahora; es un esbozo apenas para seguir pensando.

Walsh escritor, periodista, militante político, amante y autor de novelas policiales era también un importante jugador de ajedrez.

No son casuales pues las alusiones al juego que incluye en el prólogo de Operación Masacre.

Figueras recoge este costado de la personalidad de Walsh: menciona el "endgame", el tramo final del juego de ajedrez, cuando quedan pocas piezas sobre el tablero y pone en boca de Walsh las siguientes palabras:

- A muchos les parece un tramo agobiante - le dijo -, porque se concentran en las limitaciones: las piezas que perdieron, la angustia ante el damero vacío. Pero, al mismo tiempo, es el momento en que un simple peón tiene más posibilidades de coronar, de convertirse en la pieza más poderosa del tablero (Figueras, 2017, p. 255).

Walsh se pregunta en el prólogo si podía volver al ajedrez y se contesta que puede hacerlo. Sin embargo, no es así: no hay retorno posible. Walsh se ha colocado en un camino sin retorno que implica (de alguna forma) la aceptación de que eso-que-se-hace (literatura o justicia) cambia algo que impide volver de la misma manera. También de que - pudiendo ser un juego: teniendo sus reglas, idioma, personajes, etc. - y volviendo al ajedrez; ese juego no es un juego meramente intelectual, no es el ajedrez de Borges y Sherlock, el misterio del cuarto cerrado, esa ecuación, sino un ajedrez a lo Marlowe, donde las piezas hacen el papel de piezas, es decir: donde las piezas no son de "una sola pieza", y donde las reglas tienen validez pero también vencimiento (vencen o caducan, tiene historia, hacen política). Y donde importa menos la "verdad" que la posibilidad de establecerla (desde otro juego, el del poder).

Operación Masacre es un texto que permite discutir acerca de cómo se cierra una historia... porque el cierre...

\begin{abstract}
Esto se vincula con otro problema central en la discusión de la forma: ¿cómo se cierra una historia?, ¿Cuál es su final? [...], porque el cierre es un modo de darle forma a la experiencia. $\mathrm{Y}$ en torno de este problema, que vincula forma y experiencia, podemos analizar la relación entre novela y narración (Piglia, 2016, p. 51).
\end{abstract}

Los varios epílogos por una parte; la incertidumbre de que sucederá con la investigación y su difusión; la suerte de la denuncia judicial, la 
intervención política en el proceso; los documentos que aparecen y los rastros que cambian el curso de los acontecimientos y sus consecuencias (el recibo de la comisaria, la fotocopia de la página 51 del libro de locutores de Radio del Estado...) exhiben angustiosamente el "problema central" del final en Operación Masacre:

¿Cómo terminar?

Porque empezar, empezaba cualquiera. Todo lo que hacía falta era dejarse llevar por el capricho o un impulso. Se alza una mano. Se da un primer paso. Se tipea una frase. Se gatilla la cámara. Se lanza un acorde. Se hace el amor. Pero, ¿y después? ¿Cómo se conduce a ese potro lanzado a través de un terreno incierto? ¿Puede uno dirigirlo a conciencia o debe, más bien, cerrar los ojos y resignarse a la posibilidad de que todo se malogre?

Nadie controlaba nada. Por eso se afana el hombre en la creación de universos acotados, sobre los que practicar la ilusión del dominio. Cosas como la literatura o el ajedrez. ¿Cuánto tiempo había transcurrido desde su última partida? Tenía la sensación de que había perdido el knack para el juego. De enfrentarse a un tablero ¿seguiría ayudándolo la pulsión por la belleza a no sucumbir al vértigo del caos?

Los meses consagrados a investigar lo había educado en la naturaleza entrópica del universo. Formaba parte de un sistema en estado precario equilibrio, que tendía a la pérdida de energía. Lo único que estaba en duda era el tiempo que tardaría el sistema en disgregarse, pero nunca su destino.

Su derrotero podía ser útil para graficar una clase sobre el tema. Había sido un hombre relativamente feliz, hasta que una decisión irreflexiva puso en marcha la cadena de hechos que conducían a su desintegración (Figueras, 2017, p. 353-354).

\section{CONCLUSIÓN}

El final de Operación Masacre (o sus finales posibles) como el final de un proceso importan sucesivas decisiones, y generan consecuencias literarias, personales, jurídicas que atraviesan a los protagonistas y al coro, que desnudan un momento y un espacio de lo real y de los textos.

Y que inevitablemente resignifican todo lo anterior, lo que pasó y lo que pudo ser... si el final hubiera sido distinto. Tengo la convicción de que aquí se abre una perspectiva apasionante para pensar cuánto hay de ficcional en el cierre de un proceso, y de allí la pregunta que me formulara: ¿las narrativas procesales toleran un final abierto? 
Hubiera querido avanzar en el análisis. Sin embargo, la potencia literaria y política de la literatura de no ficción de Rodolfo Walsh son difíciles de superar.

Volver a las páginas de Operación Masacre fue como una trampa conmocionante de la que no pude salir y quedará para otra ocasión profundizar en ese análisis que apenas he sugerido.

\section{REFERENCIAS}

FIGUERAS, Marcelo. El negro corazón del crimen. Buenos Aires: Alfaguara, 2017.

FOUCAULT, Michel. Obrar mal, decir la verdad: La función de la confesión en la justicia. Buenos Aires: Editorial Siglo XXI, 2014.

LINK, Daniel. Leyendo «Operación Masacre». Disponible en: $<$ https://www.clubensayos.com/Informes-de-Libros/LeyendoOperaci\%C3\%B3n-Masacre/117843.html>. Acceso em: 25 Sept. 2017.

MARÍ, Enrique. Papeles de filosofía. Buenos Aires: Biblos, 1993.

PIGLIA, Ricardo. Las tres vanguardias: Saer, Puig, Walsh. Buenos Aires: Eterna Cadencia, 2016.

WALSH, Rodolfo. Operación masacre. Buenos Aires: Ediciones de la Flor, 1972.

Lengua original: Español

Recibido: 31/10/17

Aceptado: 19/12/17 